\title{
Efficacy of Biofumigation with Brassica carinata Commercial Pellets (BioFence) to Control Vegetative and Reproductive Structures of Phytophthora cinnamomi
}

\author{
C. Morales-Rodríguez, Pathology of Woody Plants. Technische Universität München, Freising 85354, Germany; and A. M. Vettraino and \\ A. Vannini, Department for Innovation in Biological, Agro-food and Forest Systems, University of Tuscia, Viterbo 01100, Italy
}

\begin{abstract}
Morales-Rodríguez, C., Vettraino, A. M., and Vannini, A. 2016. Efficacy of biofumigation with Brassica carinata commercial pellets (BioFence) to control vegetative and reproductive structures of Phytophthora cinnamomi. Plant Dis. 100:324-330.

The efficacy of biofumigation with Brassica carinata pellets (BioFence) to control vegetative and reproductive structures of Phytophthora cinnamomi was investigated in vitro at different doses and temperatures. Biofumigation was effective in inhibiting mycelial growth (culture diameter) and chlamydospore and zoospore germination, and was lethal at $24 \mathrm{mg}$ of pellet per plate (approximately $0.4 \mathrm{mg} / \mathrm{liter}$ ). The $50 \%$ effective concentration values showed that efficacy of $B$. carinata pellets in inhibiting or killing the vegetative and reproductive structures of

P. cinnamomi was maximum at $15^{\circ} \mathrm{C}$ and decreased as temperature rose to $25^{\circ} \mathrm{C}$. However, the fungicide effect was independent of the temperature. In vivo biofumigation of Quercus cerris seedlings with BioFence confirmed efficacy by reducing the inoculum density (CFU/g) of $P$. cinnamomi, thus protecting the host from root infection. The use of BioFence provides an alternative to synthetic pesticides to control $P$. cinnamomi within disease management programs in agroforestry systems.
\end{abstract}

Phytophthora cinnamomi is among the most destructive pathogens associated with the decline of forest, ornamental, and fruit species worldwide (Ferraris et al. 2004). In Europe, it is known to be responsible for extensive mortality of Quercus ilex L. and $Q$. suber L. in the "dehesa", an important agroforestry ecosystem and cultural landscape used primarily for grazing and production of nontimber forest products such as wild game, mushroom, honey, cork, and firewood (Oppermann et al. 2012). The pathogen has been also associated with deteriorating crown status of $Q$. alba L. (Balci et al. 2007), stem cankers of $Q$. cerris L. (Oh et al. 2011) and Q. laurifolia Michx. (Wood and Tainter 2002), and ink disease of Q. rubra L. (Robin et al. 1992). Furthermore, P. cinnamomi is recognized as a primary pathogen of Castanea sativa L. and Juglans spp. in Europe (Gentile et al. 2009).

Climatic variables, including winter and summer temperature, precipitation regime, and host susceptibility, can determine the aggressiveness of the pathogen (Marçais et al. 1993; Robin et al. 1992; Shearer and Tippett 1989). In a scenario of global warming, the increase of temperature is likely to increase the impact of $P$. cinnamomi due to more favorable conditions for overwintering and spread (Bergot et al. 2004). $P$. cinnamomi is disseminated through zoospore or chlamydospore production in soil and water and as mycelial growth by root-to-root contact (Shearer and Tippett 1989). Furthermore, activities such as road building, timber harvesting, mining, bush walking, and movement of wild native and feral animals have also been implicated in its dispersal (Colquhoun and Hardy 2000). Once established, it is unlikely that $P$. cinnamomi can be eradicated from natural ecosystems, because it can survive in the soil profile and in tolerant hosts.

Currently, the use of chemicals together with quarantine and hygiene practices are the only control methods available. However, increasing restrictions on the utilization of synthetic pesticides in natural and naturalized ecosystems, owing to their adverse effects in the

Corresponding author: C. Morales-Rodríguez;

E-mail: moralescorreo@ hotmail.com

Accepted for publication 13 July 2015.

http://dx.doi.org/10.1094/PDIS-03-15-0245-RE

(C) 2016 The American Phytopathological Society environment and human health (Du Fretay et al. 2010), have created new interests in alternative methods to control soilborne pathogens. In this context, biofumigation performed by the incorporation of Brassicaceae plants as fresh biomass or pellets into the soil appears promising to control Phytophthora diseases. Brassica plants contain high concentrations of glucosinolates (GSL) in specific GSL-rich cell types that are part of the natural defense systems of these plants (Koroleva et al. 2010). These molecules are a substrate for hydrolytic enzymes (myrosinases) stored in vacuoles or specific myrosin cells of Brassicaceae plants. Following tissue disruption, GSL come into contact with myrosinases and are hydrolyzed to isothiocyanates (ITC). The ITC are known to have broad biocidal activity, including insecticide, nematicide, fungicide, and phytotoxic effects (Brown and Morra 1997; Rosa et al. 1997). The chemical composition of mustard (Brassica carinata) seed meal has previously been characterized and found to contain GSL at $163.4 \mathrm{~mol} / \mathrm{g}, 98 \%$ of type 2-propenyl GSL (sinigrin), and a sufficient level of myrosinase enzyme to catalyze GSL hydrolysis (Leoni et al. 2004). Environmental risks from biofumigation are low because both GSL and ITC are short-lived in soil, with a rapid decline in concentration within the first few days. Persistence of the active molecules is up to 14 days; therefore, they do not tend to accumulate and the risk of leaching is low (Gimsing and Kirkegaard 2009).

Thus far, few studies concerning biofumigation have focused on its efficacy against soilborne Phytophthora spp. Morales-Rodríguez et al. (2012) reported that fresh tissues of Sinapis alba, B. carinata, $B$. nigra, and $B$. oleracea were effective in inhibiting the mycelial growth of $P$. nicotianae. Dunne et al. (2003) reported the suppressed growth of $P$. cinnamomi, $P$. cactorum, $P$. citricola, $P$. cryptogea, and $P$. megasperma with $B$. juncea and a mixture of two varieties of $B$. napus tissues. Mattner et al. (2008) examined the effect of biofumigation in strawberry production. In vitro bioassays indicated that volatiles from macerated roots of $B$. rapa and B. napus suppressed the growth of seven soilborne pathogens, including $P$. cactorum. However, rotary incorporation of these Brassicacaeae spp. as a green manure did not reduce the survival of $P$. cactorum. In contrast, biofumigation with rapeseed meal decreased the disease incidence of $P$. capsici in a pepper crop (Wang et al. 2014). Ríos et al. (2012) found that fresh tissues of $B$. carinata completely inhibited $P$. cinnamomi mycelial growth and inhibited sporangial production by more than $90 \%$ compared with controls. They attributed this effect to sinigrin activity. 
In this study, a commercial Brassica pellet, BioFence (Triumph Italia SPA), was tested for its ability to manage $P$. cinnamomi. BioFence is produced from $B$. carinata selection ISCI 7 using a proprietary partial defatting method that limits GSL and myrosinase degradation (Lazzeri et al. 2004). The use of this product avoids the need to grow a Brassicaceae rotation crop together with all the work that entails (plant seed, crop maintenance, and incorporation into the soil). The use of the "pelleted" biofumigant in reported to have a positive and durable effect as a soil fertilizer (http://www.triumphitalia.com). Moreover, the use of the pelleted biofumigant overcomes some of the limitations of biofumigation with fresh plants, because fresh biomass needs to be ruptured before high concentrations of ITC are released into the soil. In pellets, the GSL-myrosinase system is not compartmentalized and ITC are formed when water is added to the treated soil. A previous study with $P$. nicotianae showed that $320 \mathrm{~g}$ of fresh $B$ carinata tissue only slightly inhibited (40\%) the culture diameter in contrast to $40 \mathrm{mg}$ of BioFence pellets, which had a fungicidal effect (Morales-Rodríguez et al. 2014).

Another important aspect of treatment is soil temperature. Because temperature affects the volatility and concentration of the ITC produced during biofumigation (Price et al. 2005) as well as myrosinase activity (Al-Turki and Dick 2003), the role of temperature in biofumigation may be extremely important. It is possible that soil temperature may dictate the best time of the year for applying the treatment.

This study presents the results of in vitro and in vivo effects of biofumigation with BioFence, a $B$. carinata commercial pellet, on the different stages of the $P$. cinnamomi life cycle.

\section{Material and Methods}

Phytophthora isolates. Three $P$. cinnamomi A2 isolates were used in this study. Two isolates, LIM and M.S.B. (GenBank accession numbers KT265813 and KT265815, respectively), were obtained from fine roots of symptomatic Q. suber in 2012 (Monte San Biagio, Central Italy), and one isolate, 27A (KT2658149), from fine roots of a symptomatic $C$. sativa tree in 2010 (Allumiere, Central Italy). To standardize physiological status and age, 2 weeks before testing, the isolates were inoculated on Lupinus luteus L. roots, reisolated on PARPH (an agar medium selective for Phytophthora spp.; Jeffers and Martin 1986), and maintained on V8 juice agar (Erwin and Ribeiro 1996 ) at $20^{\circ} \mathrm{C}$.

In vitro inhibition tests. Trials were conducted using BioFence pellets ( $4 \mathrm{~mm}$ in diameter and 3 to $7 \mathrm{~mm}$ in length) according to the protocol described by Morales-Rodríguez et al. (2014). For use, the pellet was crumbled with a mortar and pestle. Five biofumigant concentrations (pellets at 0,3,6,12, and $24 \mathrm{mg} / \mathrm{plate}$ ) for culture diameter and chlamydospore germination and six concentrations (pellets at $0,2,4,6,12$, and $24 \mathrm{mg} /$ plate) for zoospore germination were compared at four different temperatures $(15,20,25$, and $30^{\circ} \mathrm{C}$ ). For each of the tests, there were five replicate plates per treatment combination. All of the in vitro experiments were repeated once and, because there were no significant differences between the experiments, the results were combined for statistical analyses.

Culture diameter. Mycelial plugs $(4 \mathrm{~mm}$ ) from actively growing colonies of the three $P$. cinnamomi isolates were placed in the center of a V8 juice agar plate $(90 \mathrm{~mm})$. All plates were incubated at $25^{\circ} \mathrm{C}$ for $24 \mathrm{~h}$ before being exposed to the biofumigation, in order to exclude the initial growth lag phase. Differentiation of vegetative and reproductive structures, including oospores, was monitored for all dose-temperature treatments at 10,15 , and 20 days after the exposure to the biofumigant.

Chlamydospore germination. Chlamydospores were produced according to the protocol reported by McCarren et al. (2009). The isolates were grown on modified Ribeiro's minimal medium (Erwin and Ribeiro 1996) at $25^{\circ} \mathrm{C}$ for 4 weeks in darkness. Once formed, the chlamydospores were suspended in sterile water by gently scraping the mycelium with a scalpel. The suspension was filtered through sterile cheesecloth and a $100-\mu \mathrm{m}$ nylon filter (adjusted to approximately 200 chlamydospores $/ \mathrm{ml}$ ) to remove the mycelium, and a 500- $\mu$ l aliquot was spread over a PARPH agar plate.
Zoospore germination. Seven mycelial plugs $(4 \mathrm{~mm})$ were cut from the margins of 5-day-old carrot agar cultures of $P$. cinnamomi isolates and incubated in $1 \%$ nonsterile soil extract. After 3 days at $25^{\circ} \mathrm{C}$, the soil extract was removed and replaced with sterile distilled water. Zoospore discharge from sporangia was initiated by placing the plates at $4^{\circ} \mathrm{C}$ for $30 \mathrm{~min}$. Concentrations of zoospores were adjusted to about 150 zoospores $/ \mathrm{ml}$ and a $500-\mu l$ aliquot was spread over a PARPH agar plate.

Biofumigant was placed on the covers of the plates inoculated with either the mycelium plug or a chlamydospore or zoospore suspension. Plates with no biofumigant treatment were used as control. Biofumigation was started by moistening the pellet with sterile distilled $\mathrm{H}_{2} \mathrm{O}(1 \mu \mathrm{l} / \mathrm{mg}$ of pellets). The plates were immediately sealed with Parafilm and incubated inverted (cover on the bottom) in the dark at each temperature $\left(15,20,25\right.$, or $\left.30^{\circ} \mathrm{C}\right)$. To evaluate the efficacy of biofumigation, the radial growth of the colonies (mean of two perpendicular diameters) and the number of colonies formed (CFU) from chlamydospore and zoospore suspensions were assessed after 3- and 6-days incubation periods for each isolate-temperature-dose treatment. To calculate the percent inhibition, radial growth or germination in the presence of biofumigant material was expressed as the mean percentage of the growth or germination in the control plates. At the end of the experiment, the cover of a plate with $100 \%$ inhibition was removed and replaced with a new one without biofumigant, and the plates were maintained for 1 month at $25^{\circ} \mathrm{C}$ to evaluate the fungicidal or fungistatic effect of biofumigant.

In vivo inhibition tests. A soil infestation test was conducted in 3-liter free-draining plastic pots, where $Q$. cerris seedlings were transplanted and grown under greenhouse conditions. $Q$. cerris is a moderately susceptible host to $P$. cinnamomi; it was chosen to better discriminate the effect of the biofumigant for both pathogen survival and host root biomass during 3 months of the experiment. The potting mix contained autoclaved peat (Vigorplant, Italy) and vermiculite $(4: 1[\mathrm{vol} / \mathrm{vol}])$. Treatments consisted of BioFence pellets in infested potting mix, BioFence pellets in uninfested potting mix, untreated infested potting mix, and untreated uninfested potting mix. BioFence pellets were applied according to the manufacturer's recommendations ( $3 \mathrm{~g} / \mathrm{liter}$ ). Treatments were applied in a random design. Inoculum was prepared by growing LIM and M.S.B. isolates of $P$. cinnamomi in flasks containing sterile millet (Panicum miliaceum L.) for 3 weeks at $20^{\circ} \mathrm{C}$ (Vettraino et al. 2003). Colonized millet grains were mixed with the potting mix at a high concentration of about $4 \%$ ( $\mathrm{vol} / \mathrm{vol})$ to observe the efficacy of the treatment under conditions of high infestation. The control seedlings received only sterile millet grains. Acorns of $Q$. cerris were pregerminated in plastic trays containing autoclaved perlite $\left(1 \mathrm{~h}\right.$ at $\left.120^{\circ} \mathrm{C}\right)$ and kept in darkness at $25^{\circ} \mathrm{C}$ and grown for 2 weeks in an environmentally controlled chamber under a photoperiod of $16 \mathrm{~h}$ of light at $25^{\circ} \mathrm{C}$ and $8 \mathrm{~h}$ of darkness at $22^{\circ} \mathrm{C}$ with a $70 \%$ relative humidity. The inoculum and the biofumigant were added simultaneously After 1 week, four $Q$. cerris seedlings/pot at the two- to three-leaf stage were transplanted into the pots. There were three replicate pots for each treatment and each isolate. Following inoculation, pots were placed into individual trays and flooded for $1 \mathrm{~h}$ before being allowed to drain freely. The pots were then placed in a greenhouse and watered weekly for the 3month duration of the trial. The experiment was repeated twice and, because there were no statistical differences between the two experiments, the results were combined for statistical analyses.

At the end of the incubation period, roots were carefully washed with water to remove the potting mix, dry weight of the root system was measured as reported by Vettraino et al. (2003), and one potting mix sample was collected from each pot to estimate germinable propagule density of Phytophthora cinnamomi as described by Jeffers and Martin (1986). A subsample $(10 \mathrm{ml})$ was added to $90 \mathrm{ml}$ of $0.3 \%$ water agar $(1: 10 \mathrm{vol} / \mathrm{vol})$ and serial dilutions were prepared $(1: 100$ and $1: 1000[\mathrm{vol} / \mathrm{vol}])$. Ten $1-\mathrm{ml}$ aliquots of this slurry from the dilutions $1: 100$ and $1: 1000(\mathrm{vol} / \mathrm{vol})$ were spread evenly onto each of $10 \mathrm{PARPH}$ plates. After 2 days of incubation in the dark at $25^{\circ} \mathrm{C}$, the diluted potting mix was washed from the plates, and macroscopically visible colonies of $P$. cinnamomi were counted. Population estimates were 
reported as number of germinable propagules per gram of dry soil (CFU/g).

Statistical analyses. Statistics was conducted using STATGRAPHICS PLUS software (version 5.1, 1994; Statistical Graphics Corp., Bekersville, MD). Significance was evaluated at $P<0.05$ for all tests.

In vitro inhibition tests. Data normality and equal variances were tested by Shapiro-Wilk and Bartlett tests, respectively. When necessary, the $\arcsin \sqrt{ } \mathrm{x}$ transformation was used to get the homoscedasticity and normality of the data (Sokal and Rohlf 1995). A Model I three-way analysis of variance (ANOVA) was performed on overall mean percentages of inhibition (culture diameter or germination) at 3 and 6 days. The three fixed factors studied were isolate, biofumigant dose, and temperature. Because of interactions between factors, twoway ANOVA (temperature and dose as fixed factors) and, afterward, one-way ANOVA (dose as fixed factor) were performed. Mean separation was accomplished by Tukey's honestly significant difference (HSD) test.

Table 1. Percent inhibition of culture diameter of three Phytophthora cinnamomi isolates at different doses of BioFence $(0,3,6,12$, and $24 \mathrm{mg} / \mathrm{plate})$ and temperatures $\left(15,20,25\right.$, and $\left.30^{\circ} \mathrm{C}\right)$

\begin{tabular}{|c|c|c|c|c|}
\hline \multirow{2}{*}{$\begin{array}{l}\text { Isolate, dose } \\
(\mathrm{mg} / \text { plate })^{\mathrm{z}}\end{array}$} & \multicolumn{4}{|c|}{$\begin{array}{l}\text { Per temperature, inhibition of culture } \\
\text { diameter }(\%) \text { at } 3 \text { days }(6 \text { days })^{y}\end{array}$} \\
\hline & $15^{\circ} \mathrm{C}$ & $20^{\circ} \mathrm{C}$ & $25^{\circ} \mathrm{C}$ & $30^{\circ} \mathrm{C}$ \\
\hline \multicolumn{5}{|l|}{$\begin{array}{l}\text { P. cinnamomi } \\
\text { LIM }\end{array}$} \\
\hline 3 & 51 a (35 a) & 46 a (33 a) & 27 a (35 a) & 18 a (0 a) \\
\hline 6 & 79 b (53 b) & 72 b (36 a) & $48 \mathrm{~b}(23 \mathrm{~b})$ & $46 \mathrm{~b}(0 \mathrm{a})$ \\
\hline 12 & $81 \mathrm{~b}(100 \mathrm{c})$ & $98 \mathrm{c}(62 \mathrm{~b})$ & $73 \mathrm{c}(21 \mathrm{~b})$ & 69 c (0 a) \\
\hline 24 & $83 \mathrm{~b}(100 \mathrm{c})$ & $100 \mathrm{~d}(100 \mathrm{c})$ & $100 \mathrm{~d}(100 \mathrm{c})$ & $100 \mathrm{~d}(100 \mathrm{~b})$ \\
\hline \multicolumn{5}{|l|}{$\begin{array}{l}\text { P. cinnamomi } \\
\text { M.S.B. }\end{array}$} \\
\hline 3 & 28 a (34 a) & 23 a (9 a) & 17 a (2 a) & 13 a (0 a) \\
\hline 6 & 79 b (56 b) & 73 b (11 a) & $32 \mathrm{~b}(3 \mathrm{a})$ & $49 \mathrm{~b}(0 \mathrm{a})$ \\
\hline 12 & $93 \mathrm{c}(100 \mathrm{c})$ & $100 \mathrm{c}(66 \mathrm{~b})$ & $72 \mathrm{c}(29 \mathrm{~b})$ & 79 c (0 a) \\
\hline 24 & $100 \mathrm{c}(100 \mathrm{c})$ & $100 \mathrm{c}(100 \mathrm{c})$ & $100 \mathrm{~d}(100 \mathrm{c})$ & $100 \mathrm{~d}(100 \mathrm{~b})$ \\
\hline \multicolumn{5}{|c|}{$\begin{array}{l}\text { P. cinnamomi } \\
27 \mathrm{~A}\end{array}$} \\
\hline 3 & 44 a (14 a) & 59 a (16 a) & 36 a (17 a) & $41 \mathrm{a}(3 \mathrm{a})$ \\
\hline 6 & $90 \mathrm{~b}(87 \mathrm{~b})$ & $96 \mathrm{~b}(30 \mathrm{~b})$ & $67 \mathrm{~b}(17 \mathrm{a})$ & $65 \mathrm{~b}(11 \mathrm{~b})$ \\
\hline 12 & $95 \mathrm{bc}(100 \mathrm{c})$ & $100 \mathrm{c}(98 \mathrm{c})$ & $92 \mathrm{c}(47 \mathrm{~b})$ & $90 \mathrm{c}(42 \mathrm{c})$ \\
\hline 24 & $100 \mathrm{c}(100 \mathrm{c})$ & $100 \mathrm{c}(100 \mathrm{c})$ & $100 \mathrm{~d}(100 \mathrm{c})$ & $100 \mathrm{~d}(100 \mathrm{~d})$ \\
\hline
\end{tabular}

${ }^{y}$ In temperature columns, numbers followed by the same letter are not significantly $(P>0.05)$ different according to Tukey's test. Culture diameter growth in presence of BioFence expressed as percentage of growth in control plates. For each set of values, the first number indicates culture diameter inhibition after 3 days of exposure to BioFence and the number in parentheses indicates culture diameter between 3 and 6 days of exposure to BioFence.

${ }^{\mathrm{z}}$ Dose of BioFence employed (milligrams of pellet per 90-mm petri plate).

Table 2. Values for $50 \%$ effective concentration $\left(\mathrm{EC}_{50}\right)$ and their fiducial limits (FL) for inhibition of radial growth of Phytophthora cinnamomi by the BioFence treatment at four temperatures (Temp; 15, 20, 25, and $30^{\circ} \mathrm{C}$ ) and between 3 and 6 days of exposure to BioFence ${ }^{z}$

\begin{tabular}{lccccr}
\hline & \multicolumn{2}{c}{3 days } & & \multicolumn{2}{c}{$\mathbf{6}$ days } \\
\cline { 2 - 3 } \cline { 5 - 6 } $\begin{array}{l}\text { Temp } \\
\left({ }^{\circ} \mathbf{C}\right)\end{array}$ & $\begin{array}{c}\mathbf{E C}_{\mathbf{5 0}} \\
(\mathbf{m g} / \mathbf{p l a t e})\end{array}$ & $\begin{array}{c}\mathbf{9 5 \%} \text { FL } \\
\text { (lower-upper) }\end{array}$ & & $\begin{array}{c}\mathbf{E C}_{\mathbf{5 0}} \\
(\mathbf{m g} / \mathbf{p l a t e})\end{array}$ & $\begin{array}{c}\mathbf{9 5 \%} \mathbf{~ F L} \\
\text { (lower-upper) }\end{array}$ \\
\hline 15 & $3.6 \mathrm{a}$ & $-5.59-4.95$ & & $4.8 \mathrm{a}$ & $3.71-5.87 \mathrm{~ns}$ \\
20 & $4.1 \mathrm{a}$ & $2.04-4.85$ & & $8.6 \mathrm{~b}$ & $6.85-10.71 *$ \\
25 & $7.2 \mathrm{~b}$ & $5.47-9.07$ & & $13.0 \mathrm{c}$ & $11.18-15.30 *$ \\
30 & $7.3 \mathrm{~b}$ & $5.22-9.34$ & & $15.8 \mathrm{c}$ & $13.65-40.79 *$ \\
\hline
\end{tabular}

${ }^{\mathrm{z}}$ Numbers in the same column followed by the same letter are not significantly different because FL overlapped; ns = no significant differences between days and $*$ indicates significant differences between days according to the FL
To evaluate the effect of temperature and time after treatment dose-inhibition regressions, $50 \%$ effective concentration $\left(\mathrm{EC}_{50}\right)$ values and their fiducial limits were estimated by probit analysis. The multiple restriction in the probit model (exclusion of variables), significance of the probit lines, and fitting of the data to the probit model were tested (likelihood ratio test, $t$-ratio test, and $\chi^{2}$ goodness-of-fit test, respectively). To determine whether the $\mathrm{EC}_{50}$ values were significantly different, the overlap of fiducial limits (95\%) was checked (Northover and Zhou 2002; Payton et al. 2003).

In vivo inhibition tests. The Mann Whitney $T$ test was used to check for significant $(P<0.05)$ differences among variances of inoculum densities (CFU/g). One-way ANOVA was performed to evaluate the differences on roots dry weight, and mean separation was accomplished by Tukey's HSD test.

\section{Results}

In vitro inhibition tests. For all the structures studied (culture diameter, chlamydospores, and zoospores), the results of a three-way ANOVA at 3 and 6 days after the treatment indicated that inhibition was significantly $(P<0.05)$ different depending on the isolate, the dose employed, and the temperature. Significant interactions were found for the interactions temperature-dose, temperature-isolate, and dose-isolate and for the triple interaction isolate-temperature-dose. In the same way, two-way ANOVA for each isolate at each date indicated that the inhibition was significantly $(P<0.05)$ different depending on the dose employed and the temperature; significant interactions were found between the factors. One-way ANOVA was performed for each isolate at each temperature for days 3 and 6 after treatment to study the effect of the dose of biofumigant.

Culture diameter. The BioFence pellets inhibited the culture diameter of all P. cinnamomi isolates (Table 1). The isolates assayed were shown to be sensitive to the effect of the biofumigant: as the biofumigant dose increased, mycelial growth inhibition increased at both 3 and 6 days of exposure. The dose of $24 \mathrm{mg}$ was fungicidal because no growth was observed once the pellets were removed and the plates were incubated for 1 month. In contrast, the other doses were fungistatic. At $30^{\circ} \mathrm{C}, 3$ - to $12-\mathrm{mg}$ doses were not effective at 6 days, with a $0 \%$ of inhibition in two of the three isolates tested.

To study the effect of temperature and time on the biofumigation efficacy of the BioFence pellets, $\mathrm{EC}_{50}$ values were calculated (Table 2). According to the likelihood ratio test, the factor isolate was not significant $(P>0.05)$; therefore, the data sets from the three isolates were combined. Concentration-response probit lines were significant $(t$-ratio test, $P<0.05)$ and data sets fitted the probit model in all cases $\left(\chi^{2}\right.$ goodness-of-fit test, $\left.P<0.05\right)$. The $\mathrm{EC}_{50}$ values increased with the increase in temperature (Table 2). At 3 days, the $\mathrm{EC}_{50}$ values at 15 and $20^{\circ} \mathrm{C}$ were lower than at 25 and $30^{\circ} \mathrm{C}$. At 6 days, all the $\mathrm{EC}_{50}$ values were significantly different, except between 25 and $30^{\circ} \mathrm{C}$. The efficacy of biofumigation to control $P$. cinnamomi growth decreased with time because the $\mathrm{EC}_{50}$ values at 6 days were significantly higher at 20,25 , and $30^{\circ} \mathrm{C}$.

Neither vegetative nor reproductive (chlamydospores, oospores, or sporangia) structures were induced by biofumigation treatments compared with the controls.

Chlamydospores germination. The $B$. carinata pellets inhibited the germination of the chlamydospores of all $P$. cinnamomi isolates (Table 3). With increasing doses of biofumigant, the inhibition of chlamydospore germination increased at 3 and 6 days of exposure. After 3 days of exposure to BioFence, an inhibition of $100 \%$ was found at $15^{\circ} \mathrm{C}$ in all the isolates regardless of the dose. No chlamydospores germinated at 12- and 24-mg doses regardless of the temperature. Only the 24-mg dose acted as a fungicide because no colonies developed after incubation at $25^{\circ} \mathrm{C}$ for 1 month without biofumigation. The $\mathrm{EC}_{50}$ values were calculated for all temperatures at 3 and 6 days (Table 4). With the likelihood ratio test, the factor isolate was not significant $(P>0.05)$ and the data sets from the three isolates were combined. Concentration-response probit lines were significant ( $t$-ratio test, $P<0.05$ ) and data sets fitted the probit model in all cases ( $\chi^{2}$ goodness-of-fit test, $P<0.05$ ), except at $15^{\circ} \mathrm{C}$ after 3 days of 
exposure, where $100 \%$ of inhibition was reached with all the doses. After both 3 and 6 days of exposure, the $\mathrm{EC}_{50}$ values increased with increases in temperature, although significant differences were not found at 3 days. The efficacy of biofumigation to inhibit chlamydospore germination of $P$. cinnamomi decreased with time because the $\mathrm{EC}_{50}$ values at 6 days were significantly higher than at 3 days at 25 and $30^{\circ} \mathrm{C}$.

Zoospore germination. For all isolates, zoospore germination was inhibited after 3 and 6 days of exposure to the different doses of BioFence, and the numbers of colonies decreased with an increase in biofumigant dose (Table 5). Zoospores germination was completely inhibited at 12 and $24 \mathrm{mg}$ at 3 days at all the temperatures studied; however, only the dose of $24 \mathrm{mg}$ was fungicidal because no colonies developed after incubation at $25^{\circ} \mathrm{C}$ for 1 month without biofumigation. Because the likelihood ratio test indicated that the factor isolate was not significant $(P>0.05)$, the data sets from the three isolates were combined when examining the $\mathrm{EC}_{50}$ values (Table 6). Concentration-response probit lines were significant ( $t$-ratio test,

Table 3. Percent inhibition of chlamydospore germination at 3 and 6 days of three isolates of Phytophthora cinnamomi at different doses $(0,2,4,6,12$, and $24 \mathrm{mg} /$ plate) and temperatures $\left(15,20,25\right.$, and $\left.30^{\circ} \mathrm{C}\right)$

\begin{tabular}{|c|c|c|c|c|}
\hline \multirow{2}{*}{$\begin{array}{l}\text { Isolate, dose } \\
(\mathrm{mg} / \text { plate })^{\mathbf{z}}\end{array}$} & \multicolumn{4}{|c|}{$\begin{array}{l}\text { Per temperature, inhibition of chlamydospore } \\
\text { germination }(\%) \text { at } 3 \text { days }(6 \text { days })^{y}\end{array}$} \\
\hline & $15^{\circ} \mathrm{C}$ & $20^{\circ} \mathrm{C}$ & $25^{\circ} \mathrm{C}$ & $30^{\circ} \mathrm{C}$ \\
\hline \multicolumn{5}{|l|}{$\begin{array}{l}\text { P. cinnamomi } \\
\quad \text { LIM }\end{array}$} \\
\hline 3 & $100(82 \mathrm{a})$ & 77 a (57 a) & 51 a (21 a) & 48 a (16 a) \\
\hline 6 & $100(95 \mathrm{~b})$ & $98 \mathrm{~b}(87 \mathrm{~b})$ & $97 \mathrm{~b}(39 \mathrm{~b})$ & $62 \mathrm{~b}(30 \mathrm{~b})$ \\
\hline 12 & $100(100 c)$ & $100 \mathrm{c}(100 \mathrm{c})$ & $100 \mathrm{c}(86 \mathrm{c})$ & $100 \mathrm{c}(74 \mathrm{c})$ \\
\hline 24 & $100(100 \mathrm{c})$ & $100 \mathrm{c}(100 \mathrm{c})$ & $100 \mathrm{c}(100 \mathrm{~d})$ & $100 \mathrm{c}(100 \mathrm{~d}$ \\
\hline \multicolumn{5}{|l|}{$\begin{array}{l}\text { P. cinnamomi } \\
\text { M.S.B. }\end{array}$} \\
\hline 3 & $100(83 a)$ & 53 a (40 a) & 32 a (19 a) & 23 a (16 a) \\
\hline 6 & $100(83 a)$ & $77 \mathrm{~b}(51 \mathrm{a})$ & $59 \mathrm{~b}(32 \mathrm{a})$ & $52 \mathrm{~b}(26 \mathrm{a})$ \\
\hline 12 & $100(100 \mathrm{~b})$ & $100 \mathrm{c}(84 \mathrm{~b})$ & $100 \mathrm{c}(61 \mathrm{~b})$ & $100 \mathrm{c}(49 \mathrm{~b})$ \\
\hline 24 & $100(100 \mathrm{~b})$ & $100 \mathrm{c}(100 \mathrm{c})$ & $100 \mathrm{c}(100 \mathrm{c})$ & $100 \mathrm{c}(100 \mathrm{c}$ \\
\hline \multicolumn{5}{|l|}{$\begin{array}{l}\text { P. cinnamomi } \\
27 \mathrm{~A}\end{array}$} \\
\hline 3 & $100(68 a)$ & 42 a (40 a) & 35 a (26 a) & 23 a (18 a) \\
\hline 6 & $100(97 \mathrm{~b})$ & $98 \mathrm{~b}(55 \mathrm{~b})$ & $83 \mathrm{~b}(50 \mathrm{~b})$ & $57 \mathrm{~b}(41 \mathrm{~b})$ \\
\hline 12 & $100(100 \mathrm{~b})$ & $100 b(100 c)$ & 100 c (62 b) & $100 \mathrm{c}(72 \mathrm{c})$ \\
\hline 24 & $100(100 \mathrm{~b})$ & $100 \mathrm{~b}(100 \mathrm{c})$ & $100 \mathrm{c}(100 \mathrm{c})$ & $100 \mathrm{c}(100 \mathrm{~d}$ \\
\hline
\end{tabular}

y For each temperature column, numbers followed by the same letter are not significantly $(P>0.05)$ different according to Tukey's test. Chlamydospore germination inhibition in presence of BioFence expressed as percentage of germination in control plates. For each set of values, the first number indicates chlamydospore germination inhibition after 3 days of exposure to BioFence and the number in parentheses indicates chlamydospore germination after 6 days of exposure to BioFence.

${ }^{z}$ Dose of BioFence employed (milligrams of pellet per 90-mm petri plate).

Table 4. Values for $50 \%$ effective concentration $\left(\mathrm{EC}_{50}\right)$ and their fiducial limits (FL) for inhibition of the chlamydospore germination of Phytophthora cinnamomi by the BioFence treatment at four temperatures (Temp; 15, 20, 25 and $\left.30^{\circ} \mathrm{C}\right)^{\mathrm{z}}$

\begin{tabular}{lccccc}
\hline & \multicolumn{2}{c}{$\mathbf{3}$ days } & & \multicolumn{2}{c}{$\mathbf{6}$ days } \\
\cline { 2 - 3 } \cline { 5 - 6 } $\begin{array}{l}\text { Temp } \\
\left({ }^{\circ} \mathbf{C}\right)\end{array}$ & $\begin{array}{c}\mathbf{E C}_{\mathbf{5 0}} \\
(\mathbf{m g} / \mathbf{p l a t e})\end{array}$ & $\begin{array}{c}\mathbf{9 5 \%} \mathbf{~ F L} \\
(\text { lower-upper) }\end{array}$ & & $\begin{array}{c}\mathbf{E C}_{\mathbf{5 0}} \\
(\mathbf{m g} / \mathbf{p l a t e})\end{array}$ & $\begin{array}{c}\mathbf{9 5 \%} \mathbf{~ F L} \\
\text { (lower-upper) }\end{array}$ \\
\hline 15 & 1.4 & $\mathrm{NA}$ & & $2.0 \mathrm{a}$ & $-2.34-3.40 \mathrm{~ns}$ \\
20 & $3.2 \mathrm{a}$ & $1.17-4.43$ & & $4.7 \mathrm{~b}$ & $1.99-6.02 \mathrm{~ns}$ \\
25 & $3.8 \mathrm{a}$ & $1.64-5.18$ & & $8.8 \mathrm{c}$ & $6.51-11.11 *$ \\
30 & $4.9 \mathrm{a}$ & $3.22-6.66$ & & $9.1 \mathrm{c}$ & $6.76-12.37 *$ \\
\hline
\end{tabular}

${ }^{\mathrm{z}} \mathrm{NA}=$ not enough data for the goodness-of-fit test. Numbers in the same column followed by the same letter are not significantly different because FL overlapped; ns $=$ no significant differences between days and $*$ indicates significant differences between both days according to the FL.
$P<0.05)$ and data sets fitted the probit model in all cases $\left(\chi^{2}\right.$ goodness-of-fit test, $P<0.05)$. The $\mathrm{EC}_{50}$ increased with temperature and time. The efficacy of biofumigation to inhibit zoospore germination of $P$. cinnamomi decreased with time because the $\mathrm{EC}_{50}$ values at 6 days were significantly higher than at 3 days at 25 and $30^{\circ} \mathrm{C}$.

In vivo inhibition test. Suppressiveness. No colonies of $P$. cinnamomi were found in controls (with and without biofumigant material). No significant differences were found among isolates; therefore, these data were combined. Biofumigated potting mixes with $307 \pm 33 \mathrm{CFU} / \mathrm{g}$ (mean \pm standard error of the mean $[$ SEM]) resulted in significantly lower inoculum densities (Mann Whitney $T$ test, $P<0.05$ ) compared with those inoculated and untreated at 4,945 $\pm 225 \mathrm{CFU} / \mathrm{g}$ (mean \pm SEM).

Root dry weight as disease indicator. After 3 months of treatment, the majority of the seedlings did not show aerial symptoms; however, the inoculated plants presented root rot. No significant differences

Table 5. Percent inhibition of zoospore germination at 3 and 6 days of three isolates of Phytophthora cinnamomi at different doses $(0,2,4,6,12$ and 24 $\mathrm{mg} / \mathrm{plate}$ ) of BioFence and temperatures $15,20,25$, and $30^{\circ} \mathrm{C}$

\begin{tabular}{lcccc}
\hline & \multicolumn{4}{c}{ Per temperature, inhibition of zoospore germination } \\
Isolate, dose & \multicolumn{4}{c}{ (\%) at 3 days (6 days) } \\
(mg/plate)
\end{tabular}

y For each temperature column, numbers followed by the same letter are not significantly $(P>0.05)$ different according to Tukey's test. Zoospore germination inhibition in presence of BioFence expressed as percentage of germination in control plates. For each set of values, the first number indicates zoospore germination inhibition after 3 days of exposure to BioFence and the number in parentheses indicates zoospore germination inhibition after 6 days of exposure to BioFence.

${ }^{\mathrm{z}}$ Dose of BioFence employed (milligrams of pellet per $90-\mathrm{mm}$ petri plate).

Table 6. Values for $50 \%$ effective concentration $\left(\mathrm{EC}_{50}\right)$ and their fiducial limits (FL) for inhibition of the zoospore germination of Phytophthora cinnamomi by the BioFence treatment at four temperatures (Temp; 15, 20, 25, and $\left.30^{\circ} \mathrm{C}\right)^{2}$

\begin{tabular}{lcclcc}
\hline & \multicolumn{2}{c}{3 days } & & \multicolumn{2}{c}{ 6 days } \\
\cline { 2 - 3 } \cline { 5 - 6 } $\begin{array}{l}\text { Temperature } \\
\left({ }^{\circ} \mathbf{C}\right)\end{array}$ & $\begin{array}{c}\mathbf{E C}_{\mathbf{5 0}} \\
(\mathbf{m g} / \mathbf{p l a t e})\end{array}$ & $\begin{array}{c}\mathbf{9 5 \%} \mathbf{F L} \\
\text { (lower-upper) }\end{array}$ & $\begin{array}{c}\mathbf{E C}_{\mathbf{5 0}} \\
(\mathbf{m g} / \mathbf{p l a t e})\end{array}$ & $\begin{array}{c}\mathbf{9 5 \%} \mathbf{~ F L} \\
\text { (lower-upper) }\end{array}$ \\
\hline 15 & $1.8 \mathrm{a}$ & $0.64-2.38$ & & $2.4 \mathrm{a}$ & $1.13-3.12 \mathrm{~ns}$ \\
20 & $2.6 \mathrm{ab}$ & $1.60-3.27$ & & $3.5 \mathrm{ab}$ & $2.54-4.35 \mathrm{~ns}$ \\
25 & $3.2 \mathrm{ab}$ & $2.02-3.95$ & & $4.8 \mathrm{~b}$ & $4.29-6.16 *$ \\
30 & $3.7 \mathrm{~b}$ & $2.79-4.01$ & & $5.4 \mathrm{~b}$ & $4.91-7.30 *$ \\
\hline
\end{tabular}

${ }^{\mathrm{z}}$ Numbers in the same column followed by the same letter are not significantly different because FL overlapped; ns = no significant differences between days and * indicates significant differences between both dates according to the FL. 
were found among isolates; therefore, the data were combined. Significant differences were found among treatments $(F=5.50, P<$ $0.05)$. According to Tukey's HSD test, seedlings in infested untreated pots showed a significant decrease in root dry weight $(0.54 \pm 0.07 \mathrm{~g})$ compared with those inoculated but biofumigated $(0.89 \pm 0.09 \mathrm{~g})$. No differences in root dry weight of seedlings were found between biofumigated infested pots and controls with and without biofumigant material $(0.92 \pm 0.11$ and $1.25 \pm 0.22 \mathrm{~g}$, respectively). $P$. cinnamomi was always reisolated from roots of seedlings in infested soil.

\section{Discussion}

In the present study, the efficacy of biofumigation with BioFence, a commercial product based on B. carinata plant material, has been demonstrated in vitro and in vivo to control the soilborne pathogen $P$. cinnamomi. The sensitivity of soilborne pathogens to biofumigation is associated with the amount of GSL produced and their hydrolyzation to ITC upon incorporation of Brassicaceae plants as fresh or pelleted material into the soil. The types, concentration, and distribution of these GSL are known to depend on the plant age and growing conditions of Brassicaceae spp. (and varieties) (Rosa et al. 1997). Additional variables such as day length and temperature determine the phenology and biomass production of brassicas (Nanda et al. 1996). Thus, the use of a standardized product such as BioFence was necessary to reduce the variability in GSL found with the use of fresh plant material. Two variables, dose and temperature, together with their interactions, were investigated to determine the efficacy of biofumigation and its potential for routine application as a management method in open fields. Suppression of $P$. cinnamomi by BioFence pellets confirmed results obtained in previous studies with other Phytophthora spp. For example, the inhibition of $P$. erythroseptica colony growth of at 100 and $26 \%$ was demonstrated by Larkin and Griffin (2007) using biofumigation with $B$. juncea and $S$. alba plant material, respectively. MoralesRodríguez et al. (2012) also demonstrated mycelial growth inhibition of $P$. nicotianae by biofumigation with plant tissues of different Brassicaceae spp. The impact of biofumigation on mycelial growth and survival is not sufficient to demonstrate its efficacy to control soilborne pathogens such us Phytophthora spp. Root infection by $P$. cinnamomi mainly depends on ability of chlamydospores to germinate and produce sporangia with infective zoospores (Erwin and Ribeiro 1996; Sanchez et al. 2002). The present study showed, for the first time, that biofumigation with BioFence can be lethal not only to $P$. cinnamomi mycelium but also to vegetative and reproductive structures.

The $\mathrm{EC}_{50}$ results show that the maximum inhibition or death of vegetative or reproductive structures occurred at $15^{\circ} \mathrm{C}$ and decreased as temperature increased. Effect of temperature on biofumigation efficacy against different organisms has been reported in several studies but with contrasting results. In a greenhouse experiment, Steffek et al. (2008) showed that the efficacy of biofumigation against Verticillium dahliae, Fusarium culmorum, and Stellaria media but not $F$. graminearum and was temperature independent between 8 and $25^{\circ} \mathrm{C}$. Matthiessen and Shackleton (2005) reported how the lethal dose of different purified ITC and Brassica tissues against whitefringed weevil larvae decreased as the temperature rose from 5 to $20^{\circ} \mathrm{C}$. Price et al. (2005) showed that the concentration of ITC from GSL hydrolysis is positively correlated with temperature; at $45^{\circ} \mathrm{C}$, the concentration of allyl ITC (AITC) in soil was $81 \%$ higher than at $15^{\circ} \mathrm{C}$. However, most of these studies monitored the efficacy of biofumigation over a maximum of $24 \mathrm{~h}$, while results of the present in vitro study refer to 6 days of exposure to biofumigant. Price et al. (2005) observed how, at $15^{\circ} \mathrm{C}$, the concentration of AITC is constant over time, with no significant differences between $0.25,4,8$, and $24 \mathrm{~h}$. However, at 30 and $45^{\circ} \mathrm{C}$, the concentration of AITC increased up to $4 \mathrm{~h}$ and decreased to $24 \mathrm{~h}$. From a biological point of view, it is possible that, at low temperatures, the myrosinase activity and the release of ITC are limited but constant in time. Conversely, the increase of temperature enhances the volatilization of ITC (Price et al. 2005). Petersen et al. (2001), in a laboratory study, showed that, in water-saturated conditions, the persistence of 2-phenylethyl ITC in soil decreases with increasing temperature. According to Henry's law, the solubility of gases generally decreases with increasing temperature. In the case of the ITC, Lim and Tung (1997) reported the negative relationship of permeability coefficients with temperature for AITC. The higher efficacy at $15^{\circ} \mathrm{C}$ of biofumigation with BioFence pellets might be explained by a higher solubilization of ITC into $P$. cinnamomi tissues.

A major outcome of the present study was to demonstrate that, although temperature affects the fungistatic efficacy of BioFence, it has no effect on the fungicidal dose. In fact, in vitro, the dose of $24 \mathrm{mg}$ caused the death of $P$. cinnamomi vegetative and reproductive structures regardless of the temperature. This result has practical implications, because it makes possible the use of biofumigation at lethal doses across a wide temperature range on different life cycle structures of the pathogen.

Vegetative (mycelium and chlamydospores) and reproductive (zoospores) structures of $P$. cinnamomi responded differently to biofumigation. In true fungi, sclerotia of Rhizoctonia solani were more tolerant to biofumigation than mycelium (Kurt et al. 2011; Yulianti et al. 2006). Vulnerability of $P$. cinnamomi chlamydospores to BioFence pellets is of particular interest for the development of control protocols for use in natural and managed ecosystems, where the chlamydospores represent the main overwintering structures of $P$. cinnamomi in the absence of oospores (Kenerley and Bruck 1983). Biofumigation with BioFence did not induce oospore formation on $P$. cinnamomi mycelium in vitro. Past studies have demonstrated that volatile (Brasier 1971) as well as nonvolatile compounds (Zentmyer 1979), produced by different fungi and plants, respectively, are able to induce sexual reproduction in unmated $P$. cinnamomi A2 isolates as well as in other heterothallic Phytophthora spp. Stimulation of oospore formation might be significant in relation to survival of the pathogen, even if Zentmyer (1979) suggested that stimulation of oospore formation parallels a lower production of sporangia that have a higher potential of disease development through the production of infective zoospores.

Variation in sensitivity to BioFence was observed among P. cinnamomi isolates in the present study. This variability has been reported by Kirkegaard et al. (1996) and Smith and Kirkegaard (2002) among isolates of different soil microorganisms. However, in the present study, only three isolates of $P$. cinnamomi were tested, although these were from different hosts and environments ( $Q$. suber forest and $C$. sativa orchards). Further analysis, including a larger number of $P$. cinnamomi isolates from different geographic origins and hosts, is needed to verify the extent of the interspecific variability.

The results of the greenhouse experiment provide more insights useful to evaluate the feasibility of an in vivo utilization of this method to manage soilborne oomycota in forest ecosystems. One of the possible risks of the biofumigation is the phytotoxic effect of ITC to the host plant, due to a nonspecific and irreversible reaction with sulfur-containing groups in proteins. Moreover, the herbicidal properties of the ITC are known (Brown and Morra 1997). Oleszek (1987) showed that volatiles from chopped Brassica spp. leaves affected germination of different test species. However, no significant differences were found after 3 months in the root dry weight between seedlings treated and untreated with BioFence in the absence of $P$. cinnamomi inoculum. This suggests that, by transplanting seedlings 1 week after the application of the biofumigant and at the dose employed ( $3 \mathrm{~g} / \mathrm{liter}$ ), BioFence has no evident phytotoxic effects to Q. cerris. After 3 months of treatment, the density of the inoculum and the disease severity in pots treated with BioFence were significantly lower than in control pots. This is new and relevant information because it provides evidence of a long-term effect of the treatment to control $P$. cinnamomi, although the protection against the arrival of new inoculum cannot be demonstrated. Similar studies have been carried out by several authors considering biofumigation with different Brassicaceae spp. other than $B$. carinata. In a test to determine the efficacy of $B$. juncea to reduce $P$. cinnamomi inoculum, Dunne et al. (2003) showed that the biofumigation decreased 
the recovery of $P$. cinnamomi but only up to 9 days after incorporation. The authors also reported the efficacy of $B$. juncea but not $B$. napus in reducing the disease incidence by $P$. cinnamomi in L. angustifolius. Utkhede and Hogue (1999) also reported that B. napus had no effect on disease incidence of Phytophthora spp. in apple.

In the in vivo test, the concentration of biofumigant employed, according to the manufacturer, was $3 \mathrm{~g} / \mathrm{liter}$, a concentration that is 10 -fold higher than the dose lethal in the in vitro tests (approximately $0.4 \mathrm{~g} /$ liter). Even at this high dose rate, a total inhibition of the pathogen was not reached and, even though the inoculum was largely reduced after 3 months, $P$. cinnamomi was always reisolated from the artificially infested soil. Matthiessen and Shackleton (2005) reported that the biological activity of 2-propenil ITC, as well as Brassica tissues, was 10-fold lower in soils than in vitro; the lowest activity was in peat at $20^{\circ} \mathrm{C}$. Moreover, the high density of inoculum used in the inoculation of plants can be the cause of not achieving total inhibition of the pathogen.

In conclusion, the present study provides encouraging evidence that BioFence provides an alternative to the use of chemicals to control $P$. cinnamomi by adversely affecting mycelial growth and viability of chlamydospores and zoospores. The potential of biofumigation as a component of the integrated management of soil pests and pathogens has previously been demonstrated in various agricultural systems. However, its use in combination with other practices (e.g., phosphite or application of antagonists) to reduce disease incidence will serve as an important part of disease management programs in agroforestry systems such as the "dehesa" or chestnut orchards.

\section{Acknowledgments}

We thank the company Triumph Italia for providing the biofumigant product used in this study, the anonymous referees for their constructive criticism, and D. W. Fulbright for the improvement of our English.

\section{Literature Cited}

Al-Turki, A., and Dick, W. 2003. Myrosinase activity in soil. Sci. Soc. Am. J. 67: 139-145.

Balci, Y., Balci, S., Eggers, J., MacDonald, W. L., Juzwik, J., Long, R. P., and Gottschalk, K. W. 2007. Phytophthora spp. associated with forest soils in eastern and north-central US oak ecosystems. Plant Dis. 91:705-710.

Bergot, M., Cloppet, E., Perarnaud, V., Deque, M., Marçais, B., and DesprezLoustau, M. L. 2004. Simulation of potential range expansion of oak disease caused by Phytophthora cinnamomi under climate change. Glob. Change Biol. 10:1539-1552.

Brasier, C. M. 1971. Induction of sexual reproduction in single A2 isolates of Phytophthora species by Trichoderma viride. Nat. New Biol. 231:283.

Brown, P. D., and Morra, M. J. 1997. Control of soil-borne plant pests using glucosinolate-containing plants. Pages 167-231 in: Advances in Agronomy, Vol. 61. Academic Press, New York.

Colquhoun, I. J., and Hardy, G. E. S. 2000. Managing the risks of Phytophthora root and collar rot during bauxite mining in the Eucalyptus marginata (Jarrah) forest of western Australia. Plant Dis. 84:116-127.

Du Fretay, G., Dasque, J., Auger, J., Coosemans, J., Colla, P., Pauwels, F., and Fritsch, J. 2010. Alterbromide: Dissemination of sustainable alternatives to methyl bromide in soil disinfestation and in postharvest in Europe. Acta Hortic. 883:113-116.

Dunne, C. P., Dell, B., and Hardy, G. E. S. 2003. The effect of biofumigants on the vegetative growth of five Phytophthora species in vitro. Pages 45-51 in: Proc. Sixth Int. Protea Res. Symp. International Society of Horticultural Science, Leuven, Belgium.

Erwin, D. C., and Ribeiro, O. K. 1996. Phytophthora Diseases Worldwide. American Phytopathological Society Press, St. Paul, MN.

Ferraris, L., Cardinale, F., Valentino, D., Roggero, P., and Tamietti, G. 2004. Immunological discrimination of Phytophthora cinnamomi from other Phytophthorae pathogenic on chestnut. J. Phytopathol. 152:193-199.

Gentile, S., Valentino, D., and Tamietti, G. 2009. Control of ink disease by trunk injection of potassium phosphite. J. Plant Pathol. 91:565-571.

Gimsing, A. L., and Kirkegaard, J. A. 2009. Glucosinolates and biofumigation: Fate of glucosinolates and their hydrolysis products in soil. Phytochem. Rev. 8:299-310.

Jeffers, S. N., and Martin, S. B. 1986. Comparison of 2 media selective for Phytophthora and Pythium species. Plant Dis. 70:1038-1043.

Kenerley, C. M., and Bruck, R. I. 1983. Overwintering and survival of Phytophthora cinnamomi in Fraser fir and cover cropped nursery beds in North-Carolina. Phytopathology 73:1643-1647.
Kirkegaard, J. A., Wong, P. T. W., and Desmarchelier, J. M. 1996. In vitro suppression of fungal root pathogens of cereals by Brassica tissues. Plant Pathol. 45:593-603.

Koroleva, O. A., Gibson, T. M., Cramer, R., and Stain, C. 2010. Glucosinolateaccumulating S-cells in Arabidopsis leaves and flowerstalks undergo programmed cell death at early stages of differentiation. Plant J. 64:456-469.

Kurt, Ş., Güneş, U., and Soylu, E. M. 2011. In vitro and in vivo antifungal activity of synthetic pure isothiocyanates against Sclerotinia sclerotiorum. Pest Manage. Sci. 67:869-875.

Larkin, R. P., and Griffin, T. S. 2007. Control of soilborne potato diseases using Brassica green manures. Crop Prot. 26:1067-1077.

Lazzeri, L., Curto, G., Leoni, O., and Dallavalle, E. 2004. Effects of glucosinolates and their enzymatic hydrolysis products via myrosinase on the root-knot nematode Meloidogyne incognita (Kofoid et White) Chitw. J. Agric. Food Chem. 52:6703-6707.

Leoni, O., Bernardi, R., Cinti, S., Malaguti, L., and Lazzeri, L. 2004. Glucosinolate degradation products in soil. Agroindustria 3:359-361.

Lim, L. T., and Tung, M. A. 1997. Vapor pressure of allyl isothiocyanate and its transport in PVDC/PVC copolymer packaging film. J. Food Sci. 62: 1061-1062.

Marçais, B., Dupuis, F., and Desprez-Loustau, M. L. 1993. Influence of water-stress on susceptibility of red oak (Quercus rubra) to Phytophthora cinnamomi. Eur. J. Forest Pathol. 23:295-305.

Matthiessen, J. N., and Shackleton, M. A. 2005. Biofumigation: Environmental impacts on the biological activity of diverse pure and plant-derived isothiocyanates. Pest Manage. Sci. 61:1043-1051.

Mattner, S. W., Porter, I. J., Gounder, R. K., Shanks, A. L., Wren, D. J., and Allen, D. 2008. Factors that impact on the ability of biofumigants to suppress fungal pathogens and weeds of strawberry. Crop Prot. 27:1165-1173.

McCarren, K. L., McComb, J. A., Shearer, B. L., and Hardy, G. E. 2009. In vitro influence of phosphite on chlamydospore production and viability of Phytophthora cinnamomi. For. Pathol. 39:210-216.

Morales-Rodríguez, C., Palo, C., Palo, E., and Rodríguez-Molina, M. C. 2014 Control of Phytophthora nicotianae with Mefenoxam, fresh Brassica tissues, and Brassica pellets. Plant Dis. 98:77-83.

Morales-Rodríguez, C., Picón-Toro, J., Palo, C., Palo, E. J., García, A., and Rodríguez-Molina, C. 2012. In vitro inhibition of mycelial growth of Phytophthora nicotianae Breda de Haan from different hosts by Brassicaceae species. Effect of the developmental stage of the biofumigant plants. Pest Manage. Sci. 68:1317-1322.

Nanda, R., Bhargava, S. C., Tomar, D. P. S., and Rawson, H. M. 1996 Phenological development of Brassica campestris, B. juncea, B. napus and $B$. carinata grown in controlled environments and from 14 sowing dates in the field. Field Crops Res. 46:93-103.

Northover, J., and Zhou, T. 2002. Control of Rhizopus rot of peaches with postharvest treatments of tebuconazole, fludioxonil, and Pseudomonas syringae. Can. J. Plant Pathol. 24:144-153.

Oh, E., Wingfield, B. D., Wingfield, M. J., and Roux, J. 2011. First report of Phytophthora cinnamomi associated with stem cankers of Quercus cerris in South Africa. New Dis. Rep. 24:11.

Oleszek, W. 1987. Allelopathic effects of volatiles from some Cruciferae species on lettuce, barnyard grass and wheat growth. Plant Soil 102:271-273.

Oppermann, R., Beaufoy, G., and Jones, G. 2012. High Nature Value Farming in Europe: 35 European Countries-Experiences and Perspectives. Verlag Regionalkultur. Ubstad-Weiher, Germany.

Payton, M. E., Greenstone, M. H., and Schenker, N. 2003. Overlapping confidence intervals or standard error intervals: What do they mean in terms of statistical significance? J. Insect Sci. 3:1-6.

Petersen, J., Belz, R., Walker, F., and Hurle, K. 2001. Weed suppression by release of isothiocyanates from turnip-rape mulch. Agron. J. 93:37-43.

Price, A. J., Charron, C. S., Saxton, A. M., and Sams, C. E. 2005. Allyl isothiocyanates and carbon dioxide produced during degradation of Brassica juncea tissue in different soil conditions. HortScience 40:1734-1739.

Ríos, P., Obregon, S., de Haro, A., Fernández, P., and Sánchez, M. E. 2012. Evaluation of biofumigant plants for control of Quercus root rot caused by Phytophthora cinnamomi in rangeland ecosystems. In: 6th Meet. IUFRO Working Party 7.02.09. Phytophthora in Forest and Natural Ecosystems. Córdoba, Spain.

Robin, C., Desprez-Loustau, M. L., and Delatour, C. 1992. Factors influencing the enlargement of trunk cankers of Phytophthora cinnamomi in red oak. Can. J. For. Res. 22:367-374.

Rosa, E. A. S., Heaney, R. K., Fenwick, G. R., and Portas, C. A. M. 1997 Glucosinolates in crop plants. Pages 99-215 in: Horticultural Reviews, Vol. 19. J. Janick, ed. John Wiley \& Sons, Inc., Oxford.

Sanchez, M. E., Caetano, P., Ferraz, J., and Trapero, A. 2002. Phytophthora disease of Quercus ilex in south-western Spain. For. Pathol. 32:5-18.

Shearer, B. L., and Tippett, J. T. 1989. Jarrah dieback: The dynamics and management of Phytophthora cinnamomi in the jarrah (Eucalyptus marginata) forest of south-western Australia. Dep. Conserv. Land Manage. Res. Bull. 3. Como, Western Australia, Australia.

Smith, B. J., and Kirkegaard, J. A. 2002. In vitro inhibition of soil microorganisms by 2-phenylethyl isothiocyanate. Plant Pathol. 51:585-593.

Sokal, R. R., and Rohlf, F. J. 1995. Biometry: The Principles and Practice of Statistics in Biological Research. W. H. Freeman, New York. 
Steffek, R., Spornberger, A., Stich, K., and Lazzeri, L. 2008. The use of brassicas to reduce inoculum potential of soil-borne pests in Austrian horticulture. In: 1st Symp. Hortic. Europe, Wien, Austria.

Utkhede, R. S., and Hogue, E. J. 1999. Influence of ground cover on development of Phytophthora crown and root rot of apple trees. Can. J. Plant Pathol. 21: 106-109.

Vettraino, A. M., Belisario, A., Maccaroni, M., and Vannini, A. 2003. Evaluation of root damage to English walnut caused by five Phytophthora species. Plant Pathol. 52:491-495.

Wang, Q., Ma, Y., Wang, G., Gu, Z., Sun, D., An, X., and Chang, Z. 2014. Integration of biofumigation with antagonistic microorganism can control
Phytophthora blight of pepper plants by regulating soil bacterial community structure. Eur. J. Soil Biol. 61:58-67.

Wood, A. K., and Tainter, F. H. 2002. First Report of Phytophthora cinnamomi on Ouercus laurifolia. Plant Dis. 86:441.

Yulianti, T., Sivasithamparam, K., and Turner, D. W. 2006. Response of different forms of propagules of Rhizoctonia solani AG2-1 (ZG5) exposed to the volatiles produced in soil amended with green manures. Ann. Appl. Biol. 148:105-111.

Zentmyer, G. A. 1979. Stimulation of sexual reproduction in the A2 mating type of Phytophthora cinnamomi by a substance in avocado roots. Phytopathology 69: 1129-1131. 